\title{
A informática na educação: o que revelam os traba- lhos publicados no Brasil
}

\author{
Informatics in education: what the works published in Brazil reveal
}

\author{
Julián E. Gutiérrez Posada \\ IC - Universidade Estadual de \\ Campinas (UNICAMP) \\ jugutier@ic.unicamp.br
}

\author{
Samuel B. Buchdid \\ IC - Universidade Estadual de \\ Campinas (UNICAMP) \\ buchdid@ic.unicamp.br
}

\author{
M. Cecília C. Baranauskas \\ IC \& NIED - Universidade Esta- \\ dual de Campinas (UNICAMP) \\ cecilia@ic.unicamp.br
}

\begin{abstract}
Resumo A comunidade de informática na educação do Brasil, tem entre seus principais eventos o Simpósio Brasileiro de Informática na Educação (SBIE), o Workshop de Informática na Escola (WIE) e, nos últimos anos, o Congresso Brasileiro de Informática na Educação (CBIE) que atualmente reúne estes dois eventos. Além disso, a revista Brasileira de Informática na Educação (RBIE) tem reunido contribuições da comunidade científica na área ao longo dos anos. Ao analisar essas fontes na Internet, observamos que todos os trabalhos publicados são de livre acesso; no entanto, é dificil construir uma visão geral dos focos de cada uma destas fontes, identificar os autores mais ativos, e determinar a quantidade e o tamanho de suas redes de cooperação. Estas informações podem ser usadas, por exemplo, para identificar os temas que estão ganhando ou perdendo relevância em cada uma destas fontes ao longo do tempo, o grau de cooperação da comunidade e linhas gerais de seu perfil. Para uma visão geral dos temas presentes nas contribuições, e como ponto de partida de uma análise mais aprofundada, este artigo utiliza o poder expressivo de tagclouds sobre os titulos dos trabalhos, assim como sobre seus resumos. Os resultados permitiram construir um roteiro dentro do campo, que pode informar os pesquisadores e profissionais que estão iniciando trabalho em áreas afins e os especialistas que querem aprofundar conhecimento sobre o tema.
\end{abstract}

Palavras-Chave: RBIE, CBIE, WIE, SBIE, visão geral, rede de autores, tagclouds

\begin{abstract}
The informatics in education community in Brazil has as its main events The Brazilian Symposium on Informatics in Education (SBIE), the Informatics in the School Workshop (WIE) and, in recent years, the Brazilian Congress of Informatics in Education (CBIE) which brings together these two events. Furthermore, the Brazilian Journal of Informatics in Education (RBIE) has gathered work from the scientific community in the area along the years. Analyzing these sources in the Internet, we see that all published works are of free access; however, it is difficult to build a view of the focuses of each of these sources, identify the most active authors, and determine the amount and size of their networks of cooperation. This information can be used for example to identify the issues that are gaining or losing relevance by each of these sources over time; estimate the degree of community cooperation and a general view of its profile. For a visual glimpse on the themes in contributions, and as a starting point of further analysis, this article uses the expressive power of tagclouds on the titles of the works, as well as on their abstracts. The results allowed us to build a roadmap within the field, which can inform researchers and practitioners who are starting to work in related fields, and even experts who want to deepen knowledge on the subject.
\end{abstract}

Keywords: RBIE, CBIE, WIE, SBIE, overview, authors network, tagclouds 


\section{Introdução}

As Tecnologias da Informação e Comunicação (TICs) estão cada vez mais presentes em ambientes públicos (ex. aeroportos e shopping centers) e privados (ex. casas e escritórios). Mais que isso, a tecnologia tem se tornado onipresente em nosso cotidiano (por exemplo, brinquedos, eletrodomésticos, carros, livros, roupas e móveis) [9]. Há muito tempo os computadores também vêm sendo incorporados ao contexto escolar, em todo o mundo, como instrumento de ensino e aprendizagem para os mais diversos assuntos [2], e também como objeto de estudo por alunos que querem aprender conceitos teóricos e práticos sobre informática e computação [17].

Nesse sentido, apenas para citar alguns exemplos, autores têm desenvolvido jogos educativos para apoiar o processo de alfabetização infantil [2] ou mesmo para introduzir conhecimentos básicos de lógica de programação e fomentar o trabalho em equipe em sala de aula [17]. Em outros casos, como em Torezani et al. [22], ambientes virtuais são criados para apoiar o processo de aprendizagem de programação de crianças do ensino fundamental. Trentin et al. [23], por sua vez, utilizam recursos da robótica de baixo custo para ensinar movimento retilíneo na área da Física. Com relação a dispositivos móveis, Luz e Fonseca [11] demonstram o uso de uma ferramenta para dispositivos móveis capaz de apoiar a aprendizagem colaborativa, que facilita a transferência de arquivos entre alunos e professores sem o uso da Internet.

Se, por um lado, a inserção das TICs em ambientes educacionais pode trazer benefícios aos alunos, por outro lado, essa inserção gera desafios que impactam diretamente na relação ensino-aprendizagem-tecnologia. Este trabalho procura identificar elementos dessa trilogia nas contribuições da comunidade Brasileira de Informática na Educação.

Para entender os interesses, a identidade e a cultura de um determinado campo de pesquisa, é importante fazer uma análise de arquivos institucionais e publicações criadas ao longo do tempo, tais como revistas, jornais e outros meios de comunicação. Essa análise pode ser utilizada para que leitores, autores, editores e pesquisadores compreendam melhor e mais objetivamente uma área de interesse [20]. Assim, este estudo tem como objetivo identificar o território de pesquisa no campo da Informática Aplicada à Educação a partir das expressões que emergem das contribuições em seus principais veículos. $\mathrm{O}$ estudo também procura enxergar as redes de cooperação dos autores. Finalmente, esta análise permite a identificação de oportunidades e temas para futuros estudos e pesquisa sobre o campo.

A literatura tem apresentado outras revisões sistemá- ticas de trabalhos no contexto de tecnologia e educação, mas com focos de pesquisa mais específicos do que o tratado neste artigo. Somente para citar alguns exemplos, Rocha et al [16] fizeram uma revisão sistemática sobre a educação de surdos em ambientes virtuais. Modesto et al [12] fizeram uma revisão sistemática para estudo da interação criança-computador associada a jogos digitais. Com foco em Problem Based Learning, Armanda et al [1] fizeram um mapeamento sistemático sobre o tema aplicado à Ciência da Computação. Ainda, Barros et al, [4] analisaram o uso de computadores no ensino fundamental e médio.

Este trabalho propõe uma análise do domínio de publicações em temas da informática na educação, inicialmente informada pelo uso de tagclouds. O estudo tem base no conteúdo de quatro fontes de pesquisa promovidas pela Comissão Especial de Informática na Educação (CEIE) da Sociedade Brasileira de Computação (SBC); são elas: i) Revista Brasileira de Informática na Educação (RBIE), ii) Simpósio Brasileiro de Informática na Educação (SBIE), iii) Workshop de Informática na Escola (WIE), e iv) Congresso Brasileiro de Informática na Educação (CBIE). Considerando-se o fato de que geralmente os títulos e resumos dos artigos representam o conteúdo da contribuição (pelo menos essa é uma recomendação aos autores na maioria das revistas e conferências), a discussão baseia-se na criação e análise de tagclouds geradas a partir de títulos e resumos de artigos encontrados no portal CEIE da SBC. Como contribuição, o documento revela características individuais do SBIE, WIE, CBIE e RBIE, suas semelhanças e diferenças, os principais focos de pesquisa sobre Informática na Educação presentes na comunidade brasileira, e sua rede de autores.

\section{Contexto do Estudo e Ferramentas}

A Revista Brasileira de Informática na Educação [14] divulga desde 1997 trabalhos acadêmicos e científicos da área da Informática na Educação. A partir de 2005 passou a ter três edições por ano. Tem por objetivo disseminar as práticas, ferramentas, e métodos que se utilizam da tecnologia no processo de ensino e aprendizagem. A revista é promovida pela Comissão Especial de Informática na Educação [8] da Sociedade Brasileira de Computação (SBC) [19].

Também mantidos pela CEIE da SBC, o Simpósio Brasileiro de Informática na Educação [18] é um evento que tem como objetivo reunir os principais interessados (ex. profissionais, professores, estudantes e pesquisadores nacionais e estrangeiros) na área de Informática na Educação para promover pesquisa e trocar experiências e ideias sobre o tema. O simpósio teve a sua primeira edição realizada em 1990 na cidade do Rio de Janeiro, e tem 
acontecido anualmente em vários estados e regiões do Brasil.

O Workshop de Informática na Escola [24] tem como principal objetivo a divulgação de iniciativas nacionais de aplicação das Tecnologias da Informação e da Comunicação nas Escolas. Nesse sentido, tem um foco de pesquisa diferenciado do SBIE, pois inclui resultados de pesquisa e prática da aplicação da tecnologia nas escolas. O evento é promovido anualmente pela Comissão Especial de Informática na Educação desde 1995.

No ano de 2011 foi criado o Congresso Brasileiro de Informática na Educação [7] que agrega diversos eventos, para apresentar resultados de pesquisas e práticas realizadas na área de Informática na Educação. Desde então o SBIE e WIE passaram a ocorrer em conjunto e fazem parte do CBIE.

Os artigos publicados na RBIE (de 1997 até 2014), no SBIE (de 2001 até 2014), no WIE (de 2003, 2005 até 2014), e no CBIE (de 2012 até 2014) serviram como base para o proposto neste trabalho de análise do campo da Informática na Educação no contexto nacional.

\subsection{Visualização dos Dados - Tag Clouds}

Tagcloud (ou nuvem de palavras) é uma representação visual para a presença de palavras (tags) em um conjunto. Cada palavra ganha destaque dentro da nuvem de acordo com sua frequência no texto; esse destaque é feito por meio da manipulação de recursos visuais, tais como tamanho da fonte, cor, etc. Dependendo do contexto em que são usados, Rivadeneira et al. [15] sugerem quatro tarefas diferentes que podem ser realizadas com tagclouds: pesquisa, navegação, formação de impressões ou gisting, reconhecimento ou correspondência. Embora as tagclouds sejam menos precisas e eficientes em alguns casos específicos que outras formas de visualização, tais como tabelas e lista de palavras, as tagclouds são vantajosas para capturar a essência de grandes quantidades de informação descritiva, apresentando-as de forma sucinta [10]. Este cenário de sucesso, motivado pela necessidade de uma análise sintética de uma grande quantidade de dados é uma das razões para a escolha de tagclouds como mecanismo de visualização de conteúdo neste trabalho.

Outros trabalhos têm utilizado tagclouds como ferramenta para as análises de conferências e publicações cientificas em outros domínios do conhecimento como em [13], [5]. Outros foram realizados com objetivos específicos para, por exemplo: identificar lacunas e oportunidades de pesquisa nas áreas de acesso universal à tecnologia [3] e TV Digital Interativa [6].

\subsection{Ferramenta Customizada para Análises de Expressões e Pesquisa - ToPA}

Uma ferramenta, ToPA (do inglês Tool for Publication Analyzes) foi criada para a análise de temas, autores e seções específicas de determinada conferência [21]. Uma vez escolhido o tema, a ferramenta mostra os artigos que estão relacionados ao tema e quais são aos seus respectivos autores. Para cada conferência, ToPA apresenta uma síntese dos autores, quantidades de artigos e expressões mais comuns que aparecem nos títulos dos artigos. Também é possível organizar as informações por ano de cada conferência, ou mesmo por vários anos de determinada conferência. Com o auxílio da ferramenta Wordle, ToPA também é capaz de gerar tagclouds das palavras e autores mais frequentes.

Entre outros processamentos, por exemplo, para fazer a contagem correta do número de autores, a ferramenta conduz um processo de normalização dos nomes e busca por semelhanças entre os nomes dos autores para padronizar a sua escrita (por exemplo: acentuações, abreviaturas, espaços). Também é possível escolher filtros que mostram somente autores com pelo menos duas publicações nas Conferências durante os anos alisados.

Outros tipos de dados também podem ser usados e mapeados pela ferramenta (ex. as instituições dos autores e país onde estão essas instituições). A ferramenta foi implementada na web para facilitar uso da comunidade de pesquisa em Informática na Educação está disponível em http://eurydice.nied.unicamp.br/ToPA/.

Em complemento, especialmente paras a análises feitas neste artigo, uma nova funcionalidade foi incorporada com a finalidade de criar tagclouds de expressões com mais de uma palavra, de acordo com a frequência com que expressões de " $n$ " palavras aparecem no texto (com "n" configurável). A análise de expressões pode partir de um número mínimo e máximo de palavras. Por exemplo, para expressões com duas palavras, o complemento da ferramenta ToPA faz a busca no texto de duas palavras consecutivas. Cada par de palavras encontrado é colocado em uma tabela, e toda vez que surge uma nova expressão uma nova entrada na tabela é adicionada. Se uma entrada já existe na tabela, a frequência daquela expressão é aumentada em uma unidade. O mesmo ocorre para expressões com mais de duas palavras. $\mathrm{O}$ algoritmo ignora as expressões que começam e terminam por preposições ou artigos. Por exemplo, "a educação" ou "Educação para" não são registradas como expressões de 2 palavras. Este complemento está disponível em http://eurydice.nied.unicamp.br/ExpressionsAnalyzer/. 


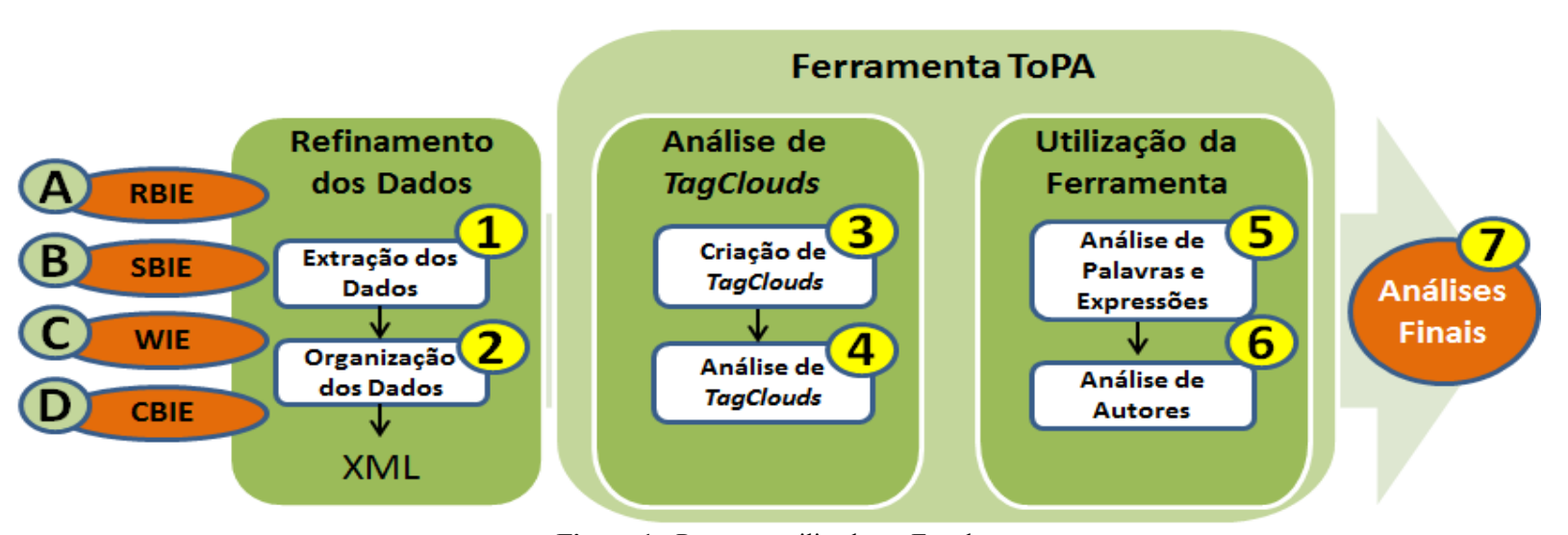

Figura 1 : Processo utilizado no Estudo

\section{Método}

O processo empregado neste estudo está dividido em grandes etapas e envolveu extração, qualificação e quantificação dos dados, e análise propriamente dita conforme mostra a Figura 1. Na primeira fase, as informações relevantes das 4 fontes foram coletadas no site da CEIE [8]. Para este estudo, entre as diversas informações existentes, usamos os dados referentes aos títulos dos artigos e seus respectivos resumos e autores. Essas informações foram extraídas de forma semiautomática, isto é, o texto do site da CEIE precisou ser copiado para outro documento e expressões regulares foram utilizadas como filtros para selecionar as informações desejadas. As informações foram organizadas e colocadas em um arquivo texto separadas por ponto e vírgula, no formato de documento CSV (do inglês, Comma-separated values). O arquivo CSV serviu como fonte de criação de um arquivo XML (do inglês, eXtensible Markup Language) compatível com a ferramenta ToPA [21] utilizada para analisar os dados (conforme descrito na subseção 2.2).

$\mathrm{Na}$ segunda fase do processo, com as informações de títulos e resumos do artigo criamos tagclouds para vários conjuntos de dados em uma estratégia específica geral, isto é, criamos tagclouds para cada ano, depois para um conjunto de anos, para todos os anos de determinada fonte (conferências e revista) e, por fim, para dados de diferentes fontes. $\mathrm{O}$ mesmo foi feito para os autores das publicações. Esta visualização a partir das tagclouds foi apenas um ponto de partida para o processo de análise; as tagclouds forneceram termos-chave que em seguida foram analisados com a ferramenta ToPA revelando alguns movimentos nos focos das contribuições.

Para discussão, escolhemos as tagclouds criadas para todos os anos de cada conferência, e todos os trabalhos publicados pelas duas conferências foram mostrados separadamente. Sobre a tagcloud de autores, esta representa os autores que tiveram mais de dois trabalhos publicados independentemente do ano. Este conjunto de tagclouds fornece uma visão geral dos temas discutidos nas obras, bem como de autores representativos.

\section{Resultados}

\begin{tabular}{|c|c|c|c|c|}
\hline Ano & RBIE & SBIE & WIE & CBIE \\
\hline 1997 & 13 & & & \\
\hline 1998 & 19 & & & \\
\hline 1999 & 19 & & & \\
\hline 2000 & 13 & & & \\
\hline 2001 & 16 & 58 & & \\
\hline 2002 & 13 & 71 & & \\
\hline 2003 & 12 & 71 & 62 & \\
\hline 2004 & 11 & 85 & - & \\
\hline 2005 & 15 & 73 & 45 & \\
\hline 2006 & 13 & 89 & 48 & \\
\hline 2007 & 15 & 135 & 40 & \\
\hline 2008 & 16 & 84 & 58 & \\
\hline 2009 & 17 & 84 & 44 & \\
\hline 2010 & 18 & 132 & 60 & \\
\hline 2011 & 20 & 138 & 71 & \\
\hline 2012 & 27 & 142 & 48 & 79 \\
\hline 2013 & 30 & 109 & 49 & 80 \\
\hline 2014 & 33 & 152 & 71 & 91 \\
\hline TOTAL & 320 & 1423 & 596 & 250 \\
\hline
\end{tabular}

Tabela 1: Distribuição do total de artigos entre os anos 1997 e 2014

No total foram processados: 2.589 trabalhos distribuídos da seguinte forma: $54,96 \%$ (1423) para SBIE; 23,02\% (596) para WIE; 9,66\% (250) para CBIE; e 
$12,36 \%$ (320) para RBIE. A Tabela 1 mostra a quantidade de publicações anuais por evento.

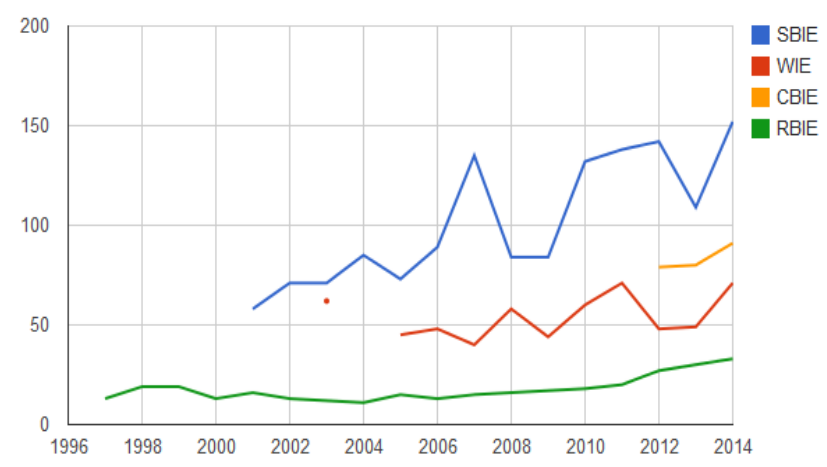

Figura 2 : Comportamento da produção de artigos

A Figura 2 mostra o comportamento da produção da comunidade, a partir da quantidade de artigos publicados entre os anos 1997 e 2014. O evento com quantidade maior de publicações por ano é o SBIE, seguido de CBIE, WIE, e, finalmente, RBIE. Observe-se que não existe informação de todos os eventos durante este tempo por duas razões principais: ou a informação não está disponível na página da Comissão Especial de Informática na Educação do Brasil (http://www.ceie.org.br/), ou o evento não existia naqueles anos.

Nas subseções seguintes apresentamos informações mais detalhadas sobre cada um dos veículos.

\subsection{RBIE (1997-2014)}

No período de 1997 a 2014, a revista RBIE agrupa 320 trabalhos de 681 autores. Os cinco autores com mais publicações na revista apresentam 8, 7, 7, 6 e 6 trabalhos, respectivamente. Uma imagem mais completa dos autores mais presentes pode ser vista na Figura 3 na forma de uma tagcloud. Aparecem na nuvem de autores com pelo menos quatro trabalhos publicados no período analisado.

O passo seguinte na análise envolveu buscar as redes de coautoria, determinar a quantidade, o tamanho, e os membros de cada uma delas.

Uma rede de coautoria é definida como uma rede fechada onde todos os membros estão direta ou indiretamente relacionados através de um ou vários trabalhos. Um autor só pode pertencer a uma rede em um determinado momento. Quando dois coautores de diferentes redes geram um artigo, imediatamente as duas redes a que pertencem, se juntam para criar uma rede maior. $\mathrm{O}$ objetivo, no final, é observar o alcance das parcerias da comunidade no evento. Neste sentido, um autor que publicou um ou mais trabalhos sem a participação de coautores pertence a uma "rede" de um só autor.

Para o caso da RBIE no período de tempo definido (1997-2014), existe um total de 165 redes de coautoria; destas redes $21,82 \%$ (36) são redes de um só autor. A Tabela 2 mostra os agrupamentos de todas as redes. A maior rede na RBIE no período é de 46 autores que representa $6,75 \%$ do total de autores.

\begin{tabular}{c|c|c}
\hline $\begin{array}{c}\text { Quantidade } \\
\text { de Autores }\end{array}$ & $\begin{array}{c}\text { Quantidade } \\
\text { de Redes }\end{array}$ & $\begin{array}{c}\text { Porcentagem do } \\
\text { total de redes }\end{array}$ \\
\hline 1 até 5 & 139 & $84,24 \%$ \\
\hline 6 até 10 & 16 & $9,70 \%$ \\
\hline 11 até 15 & 2 & $1,21 \%$ \\
\hline 16 até 20 & 4 & $2,42 \%$ \\
\hline 21 até 25 & 2 & $1,21 \%$ \\
\hline 26 ou mais & 2 & $1,21 \%$ \\
\hline
\end{tabular}

Tabela 2: Redes de coautoria do RBIE (1997-2014)

Se procurarmos a rede a que pertence cada um dos cinco autores mais presentes, podemos afirmar que o primeiro, o terceiro e o quinto autor pertencem à mesma rede (a maior rede), enquanto, o segundo pertence a uma rede de 23 autores; e o quarto autor pertence a uma rede de 16 autores.

É possível consultar a ferramenta ToPA online para realizar esta e outras consultas, como por exemplo exibir

\section{Léa da Cruz Fagundes \\ Hugo FukS Lucila Maria Costi Santarosa Ig lbert Bittencourt Rosa Maria Viccari \\ André Luís Alice Raabe Jorge Luis Victória Barbosa Seiji Isotani Carlos José Pereira de LucenaPatrícia Alejandra Behar Fábio Ferrentini Sampaio Sean Wolfgand Matsui Siqueira Alex Sandro Gomes Maria Cecilia Calani Baranauskas Alexandre lbrahim Direne Marisa LucenaSérgio Crespo C. S. Pinto Heloísa Vieira da RochaLiliana Maria Passerino Crediné Silva de Menezes Lúcia Maria Martins Giraffa Evandro Costa Marco Aurélio Gerosa}

Figura 3 : Os autores mais frequentes na RBIE (1997-2014) 


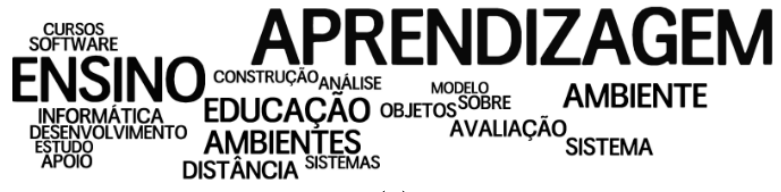

(a)

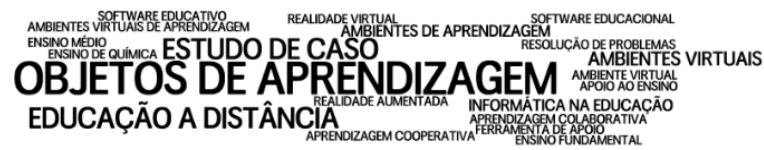

(c)

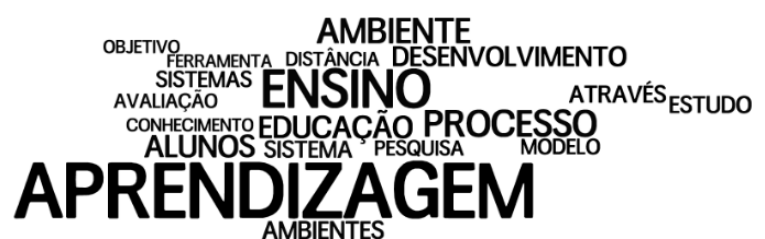

(b)

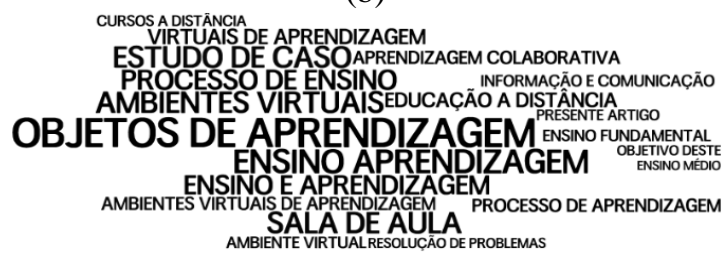

(d)

Figura 4 : Tagclouds dos títulos e dos resumos do RBIE no período (1997-2014): a) palavras recorrentes nos títulos, b) palavras recorrentes nos resumos; c) expressões recorrentes nos títulos, d) expressões recorrentes nos resumos

as conexões entre dois autores.

Para descobrir o que os títulos e os resumos dos trabalhos revelam, geramos dois tipos de tagclouds: uma que considera apenas as palavras individualmente dos títulos (Figura 4-a) e dos resumos (Figura 4-b); e outra que considera as expressões mais recorrentes nos títulos (Figura 4-c) e nos resumos (Figure 4-d).

Nas Figuras 4-a e 4-b APRENDIZAGEM e ENSINO são as palavras de maior destaque. Para encontrar os contextos de uso delas, buscamos extrair as expressões mais comuns nos títulos (Figura 4-c) e nos resumos (Figura 4-d).

As Figuras 4-c e 4-d mostram um contexto para as palavras mais relevantes; como ilustração, a palavra APRENDIZAGEM aparece como a substância e contraparte do Ensino (ex. Ensino e Aprendizagem, Aprendizagem Colaborativa), e principalmente como qualificador em: Objetos de Aprendizagem, Ambientes Virtuais de Aprendizagem, Processo de Aprendizagem, Ambientes de Aprendizagem. Para o caso da palavra ENSINO, esta qualifica Processo e categoriza os principais focos nos níveis Médio e Fundamental (Ensino Médio, Ensino Fundamental).

Note-se que uma fonte de artigos pode ter uma base bastante diversificada de temas, tão variados que o número de palavras mais frequentes é baixo com relação ao total. Por exemplo, a palavra AVALIAÇÃO aparece em $5.63 \%$ dos títulos de trabalhos. Ainda, pode acontecer é que a fonte tem um conjunto pequeno de temas diferentes, de modo que o valor da frequência destas palavras é alto. No caso das palavras APRENDIZAGEM e ENSINO, que aparecem nos títulos de 75 e 61 trabalhos, a porcentagem relativa dos trabalhos é de $23.44 \%$ e $19.06 \%$, respectivamente.

A Tabela 3 mostra as expressões mais frequentes que aparecem ao longo dos anos para a revista RBIE.

\begin{tabular}{|c|c|c|c|}
\hline 1997-2002 & 2003-2006 & 2007-2010 & 2011-2014 \\
\hline $\begin{array}{c}\text { EDUCACÃO A } \\
\text { DISTANNCIA } \\
\left(4,3 \frac{\circ}{0}\right)\end{array}$ & $\begin{array}{c}\text { EDUCACÃO A } \\
\text { DISTÂNCIA } \\
(5,9 \%)\end{array}$ & $\begin{array}{c}\text { OBJETOS DE } \\
\text { APRENDIZAGEM } \\
(12,1 \%)\end{array}$ & $\begin{array}{l}\text { ESTUDO DE } \\
\text { CASO } \\
\left(6,4 \frac{\circ}{6}\right)\end{array}$ \\
\hline $\begin{array}{c}\text { AMBIENTES } \\
\text { COMPUTACIONAIS } \\
(4,3 \%)\end{array}$ & $\begin{array}{l}\text { AMBIENTE } \\
\text { TELEDUC } \\
(3,9 \%)\end{array}$ & $\begin{array}{l}\text { AMBIENTE } \\
\text { VIRTUAIS } \\
(6,0 \%)\end{array}$ & $\begin{array}{c}\text { OBJETOS DE } \\
\text { APRENDIZAGEM } \\
(5,5 \%)\end{array}$ \\
\hline $\begin{array}{c}\text { APRENDIZAGEM } \\
\text { COOPERATIVA } \\
(3,2 \%)\end{array}$ & $\begin{array}{c}\text { AMBIENTES DE } \\
\text { APRENDIZAGEM } \\
(3,9 \%)\end{array}$ & $\begin{array}{c}\text { ANÁLISE DA } \\
\text { APRENDIZAGEM } \\
(3,0 \%)\end{array}$ & $\begin{array}{c}\text { APOIO AO } \\
\text { ENSINO } \\
(3,6 \%)\end{array}$ \\
\hline $\begin{array}{l}\text { CONCEITOS } \\
\text { VISUAIS } \\
(3,2 \%)\end{array}$ & $\begin{array}{c}\text { APOIO À } \\
\text { APRENDIZAGEM } \\
(3,9 \%)\end{array}$ & $\begin{array}{l}\text { APRENDIZAGEM } \\
\text { SIGNIFICATI- } \\
\text { VA }\end{array}$ & $\begin{array}{c}\text { AMBIENTES } \\
\text { VIRTUAIS DE } \\
\text { APRENDIZAGEM }\end{array}$ \\
\hline $\begin{array}{c}\text { INFORMÁTICA NA } \\
\text { EDUCACẼO } \\
(3,2 \%)\end{array}$ & $\begin{array}{c}\text { APRENDIZAGEM } \\
\text { COLABORATIVA } \\
(3,9 \%)\end{array}$ & $\begin{array}{c}(3,0 \%) \\
\text { AVALIAÇ̃O DE } \\
\text { SOFTWARE }\end{array}$ & $\begin{array}{l}\text { ENSINO DE } \\
\text { QUİICA }\end{array}$ \\
\hline $\begin{array}{c}\text { REALIDADE } \\
\text { VIRTUAL } \\
(3,2 \%)\end{array}$ & $\begin{array}{c}\text { AVALIAÇÃO } \\
\text { FORMATIVA } \\
(3,9 \%)\end{array}$ & $\begin{array}{c}\text { EDUCATIVO } \\
(3,0 \%) \\
\text { REDES DE }\end{array}$ & $\begin{array}{l}\text { ENSINO MÉDIO } \\
(2,7 \%)\end{array}$ \\
\hline $\begin{array}{c}\text { AMBIENTE } \\
\text { AULANET } \\
(2,2 \%)\end{array}$ & $\begin{array}{l}\text { CURSOS } \\
\text { ONLINE } \\
(3,9 \%)\end{array}$ & $\begin{array}{c}\text { PETRI } \\
\text { COLORIDAS } \\
(3,0 \%)\end{array}$ & $\begin{array}{c}\text { FERRAMENTA } \\
\text { DE APOIO } \\
(2,7 \%)\end{array}$ \\
\hline $\begin{array}{c}\text { AMBIENTES PARA } \\
\text { CONSTRUČ̃̃O } \\
(2,2 \%)\end{array}$ & $\begin{array}{c}E S T U D O \\
D E C A S O \\
(3,9 \%)\end{array}$ & $\begin{array}{c}\text { RESOLUÇÃO DE } \\
\text { PROBLEMAS } \\
(3,0 \%)\end{array}$ & $\begin{array}{l}\text { REALIDADE } \\
\text { AUMENTADA } \\
(2,7 \% 0)\end{array}$ \\
\hline $\begin{array}{c}\text { AVALIAÇ̃̃O } \\
\text { PEDAGÓGICA } \\
(2,2 \%)\end{array}$ & $\begin{array}{c}\text { MAPAS } \\
\text { CONCEITUAIS } \\
(3,9 \%)\end{array}$ & & $\begin{array}{c}\text { ANÁLISE DAS } \\
\text { INTERACÕ̃ES } \\
(1,8 \%)\end{array}$ \\
\hline $\begin{array}{c}\text { SOFTWARE EDUCA- } \\
\text { CIONAL } \\
(2,2 \%)\end{array}$ & $\begin{array}{c}\text { MÍDIAS } \\
\text { DIGITAIS } \\
(3,9 \%)\end{array}$ & & $\begin{array}{c}\text { APRENDIZAGEM } \\
\text { UBÍQUA } \\
(1,8 \%)\end{array}$ \\
\hline
\end{tabular}

A Tabela 3 mostra o movimento dos grandes temas ao longo dos anos: EDUCAÇÃO A DISTÂNCIA com grande frequência até 2006, destacando-se no período, em particular CURSOS ONLINE e os ambientes AULANET e TELEDUC; ainda, OBJETOS DE APRENDIZAGEM surgindo a partir de 2007 e destacando-se ao longo dos dois últimos períodos. Nos anos mais recentes aparecem expressões que fazem menção a tecnologias avançadas (ex. REALIDADE AUMENTADA) e a computação ubíqua (APRENDIZAGEM UBÍQUA), embora aspectos de tecnologia já tivessem destaque nos anos iniciais (ex. REALIDADE VIRTUAL), o que mostra a preocupação constante da comunidade de pesquisa com os avanços da tecnologia. 


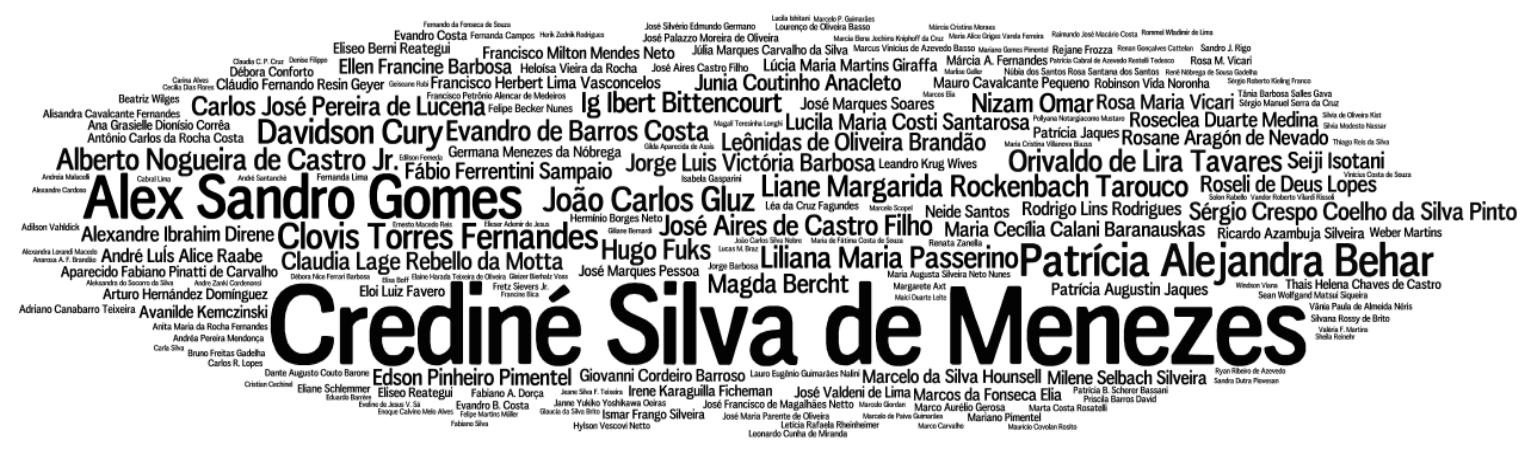

Figura 5 : Os autores mais frequentes do SBIE (2001-2014)

Avaliação tem sido um tema constante ao longo dos anos (AVALIAÇÃO PEDAGÓGICA, AVALIAÇÃO FORMATIVA, AVALIAÇÃO DE SOFTWARE EDUCATIVO), além de análises de diversos tipos nos dois últimos períodos (ANÁLISE DA APRENDIZAGEM, ANALISE DAS INTERAÇÕES). Enquanto Análise e Avaliação se destacam, o mesmo não ocorre com Design ou Projeto, que são partes do processo de Construção de sistemas e ambientes tecnológicos ou educacionais.

Com relação a veículos e representações do conhecimento, destacam-se CONCEITOS VISUAIS, MAPAS CONCEITUAIS, MÍDIAS DIGITAIS, e REDES DE PETRI.

Aspectos metodológicos de pesquisa são mais evidenciados no período 2003-2006 (ESTUDO DE CASO).

Finalmente, mas não menos importante, observam-se os qualificativos para APRENDIZAGEM ao longo dos 4 períodos, passando por: COOPERATIVA, COLABORATIVA, SIGNIFICATIVA, e UBÍQUA.

\subsection{SBIE (2001-2014)}

No período de tempo considerado (2001-2014), o SBIE agrupa 1423 trabalhos de 2933 autores. Os cinco autores com mais publicações no simpósio contribuíram com 58, 32, 24, 19 e 18 trabalhos, respectivamente. A Figura 5 apresenta a tagcloud dos autores com pelo menos quatro trabalhos publicados no período analisado.

Com relação a redes de coautoria, existem 349 redes, das quais $8.31 \%$ (29) são de uma só pessoa. A Tabela 4 mostra os agrupamentos de todas as redes. Vale a pena observar que entre as 6 redes com mais de 26 autores existe uma rede que agrupa $47,83 \%$ (1403) dos autores do SBIE.

\begin{tabular}{c|c|c}
\hline $\begin{array}{c}\text { Quantidade } \\
\text { de } \text { Autores }\end{array}$ & $\begin{array}{c}\text { Quantidade } \\
\text { de Redes }\end{array}$ & $\begin{array}{c}\text { Porcentagem do } \\
\text { total de redes }\end{array}$ \\
\hline 1 até 5 & 280 & $80,23 \%$ \\
\hline 6 até 10 & 54 & $15,47 \%$ \\
\hline 11 até 15 & 4 & $1,15 \%$ \\
\hline 16 até 20 & 2 & $0,57 \%$ \\
\hline 21 até 25 & 3 & $0,86 \%$ \\
\hline 26 ou mais & 6 & $1,72 \%$ \\
\hline
\end{tabular}

Tabela 4: Redes de coautoria do SBIE (2001-2014)

Se procurarmos as redes a que pertencem os cinco autores com mais publicações neste evento, descobrimos que todos eles, exceto o quarto, pertencem à rede de maior tamanho (1403 autores). O quarto autor mais presente

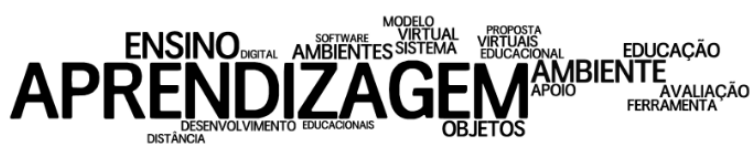

(a)

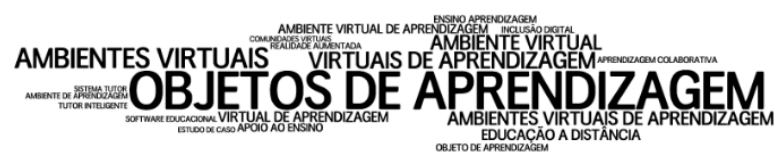

(c)

\section{APRENDIZAGEM Mam PROCESSO AMBIENTEN
SOFTWRE AVALIAO DISTNCIA EDUCACIONAL APOIO AMBIENTE ENSINO}

(b)

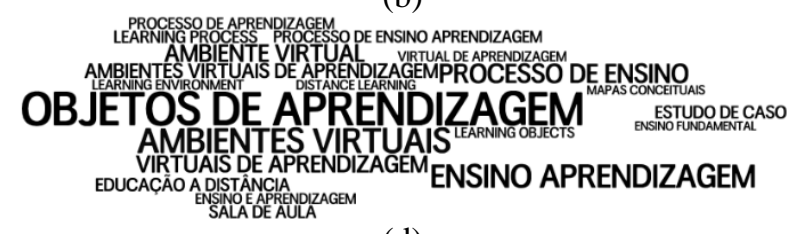

(d)

Figura 6 : Tagcloud dos títulos e dos resumos do SBIE (2001-2014) a) palavras recorrentes nos títulos, b) palavras recorrentes nos resumos; c) expressões recorrentes nos títulos, d) expressões recorrentes nos resumos 
pertence a uma rede com 82 autores.

Analisando a palavra mais frequente, APRENDIZAGEM (Figuras 6-a e 6-b), encontramos os contextos de: Objetos de Aprendizagem, Ambientes Virtuais de Aprendizagem, Aprendizagem Colaborativa (Figuras 6-c e 6-d). São os mesmos contextos encontrados na RBIE.

A Tabela 3 mostra o movimento dos grandes temas ao longo dos anos: EDUCAÇÃO A DISTÂNCIA com grande frequência até 2010; diferentemente do ocorrido com a RBIE, menções a plataformas de Educação a Distância, não são frequentes no SBIE. Também diferentemente dos resultados para a RBIE, SISTEMA TUTOR INTELIGENTE aparece com frequência até 2006. AMBIENTES VIRTUAIS é a expressão frequente ao longo de todos os períodos, que parece denotar as diferentes modalidades de sistemas de apoio ao processo de ensino/aprendizagem.

\begin{tabular}{|c|c|c|c|}
\hline $2001-2002$ & $2003-2006$ & $2007-2010$ & $2011-2014$ \\
\hline $\begin{array}{c}\text { AMBIENTE }(S) \\
\text { VIRTUAIS } \\
(6,2 \circ)\end{array}$ & $\begin{array}{c}\text { AMBIENTE }(S) \\
\text { VIRTUAIS } \\
\left(5,3 \frac{8}{\circ}\right)\end{array}$ & $\begin{array}{c}\text { OBJETO (S) DE } \\
\text { APRENDIZAGEM } \\
(11,0 \%)\end{array}$ & $\begin{array}{c}\text { OBJETOS DE } \\
\text { APRENDIZAGEM } \\
(10,4 \%)\end{array}$ \\
\hline $\begin{array}{c}\text { AMBIENTES DE } \\
\text { APRENDIZAGEM } \\
(3,1 \%)\end{array}$ & $\begin{array}{c}\text { OBJETOS DE } \\
\text { APRENDIZAGEM } \\
(3,8 \%)\end{array}$ & $\begin{array}{c}\text { AMBIENTE }(S) \\
\text { VIRTUAIS } \\
(7,8 \%)\end{array}$ & $\begin{array}{c}\text { AMBIENTE }(S) \\
\text { VIRTUAIS } \\
(7,0 \%)\end{array}$ \\
\hline $\begin{array}{c}\text { APRENDIZAGEM } \\
\text { COOPERATIVA } \\
\left(3,1 \frac{1}{0}\right)\end{array}$ & $\begin{array}{c}\text { COMUNIDADES } \\
\text { VIRTUAIS } \\
\left(2,8 \frac{8}{8}\right)\end{array}$ & $\begin{array}{c}\text { EDUCACÃO A } \\
\text { DISTÂNCIA } \\
(2,8 \circ)\end{array}$ & $\begin{array}{c}\text { APOIO AO } \\
\text { ENSINO } \\
(3.0 \%)\end{array}$ \\
\hline $\begin{array}{c}\text { SOFTWARE } \\
\text { EDUCACIONAL } \\
(3,1 \%)\end{array}$ & $\begin{array}{c}\text { EDUCAÇÃO A } \\
\text { DISTÂNCIA } \\
\left(2,5 \frac{8}{\circ}\right)\end{array}$ & $\begin{array}{l}\text { INCLUSÃO } \\
\text { DIGITAL } \\
(\mathbf{2}, \mathbf{3} 8)\end{array}$ & $\begin{array}{c}\text { MAPEAMENTO } \\
\text { SISTEMÁTICO } \\
(2.4 \%)\end{array}$ \\
\hline $\begin{array}{c}\text { AMBIENTE } \\
\text { COOPERATIVO } \\
\left(2,3 \frac{2}{0}\right)\end{array}$ & $\begin{array}{c}\text { AMBIENTE DE } \\
\text { APRENDIZAGEM } \\
(2,2 \circ)\end{array}$ & $\begin{array}{c}\text { ENSINO } \\
\text { APRENDIZAGEM } \\
(1,8 \%)\end{array}$ & $\begin{array}{c}\text { REALIDADE } \\
\text { AUMENTADA } \\
(2,0 \%)\end{array}$ \\
\hline $\begin{array}{c}\text { AMBIENTE DE } \\
\text { ENSINO } \\
\left(2,3 \frac{8}{8}\right)\end{array}$ & $\begin{array}{l}\text { INCLUSÃO } \\
\text { DIGITAL } \\
(2,2 \%)\end{array}$ & $\begin{array}{c}\text { APRENDIZAGEM } \\
\text { COLABORATIVA } \\
(1,6 \%)\end{array}$ & $\begin{array}{c}\text { REVISÃO } \\
\text { SISTEMÁTICA } \\
(1,8 \%)\end{array}$ \\
\hline $\begin{array}{c}\text { APRENDIZAGEM } \\
\text { COLABORATIVA } \\
(2,3 \%)\end{array}$ & $\begin{array}{c}\text { REALIDADE } \\
\text { VIRTUAL } \\
(2,2 \%)\end{array}$ & $\begin{array}{c}\text { ESTUDO DE } \\
\text { CASO } \\
(1,6 \%)\end{array}$ & $\begin{array}{c}\text { REDES } \\
\text { SOCIAIS } \\
\left(1,7 \frac{\circ}{6}\right)\end{array}$ \\
\hline $\begin{array}{c}\text { COMUNIDADES } \\
\text { VIRTUAIS } \\
\left(2,3 \frac{8}{8}\right)\end{array}$ & $\begin{array}{c}\text { TUTOR } \\
\text { INTELIGENTE } \\
(1,9 \%)\end{array}$ & $\begin{array}{c}\text { MAPAS CON- } \\
\text { CEITUAIS } \\
(1,6 \%)\end{array}$ & $\begin{array}{c}\text { DISPOSITIVOS } \\
\text { MÓVEIS } \\
\left(1,5 \frac{1}{8}\right)\end{array}$ \\
\hline $\begin{array}{c}\text { EDUCAÇ̃̃O A } \\
\text { DISTÂNCIA } \\
\left(2,3 \frac{0}{\circ}\right)\end{array}$ & $\begin{array}{c}\text { MAPAS } \\
\text { CONCEITUAIS } \\
(1,6 \%)\end{array}$ & $\begin{array}{c}\text { DEFICIENTES } \\
\text { VISUAIS } \\
(1,1 \text { 음 })\end{array}$ & $\begin{array}{c}\text { ENSINO E } \\
\text { APRENDIZAGEM } \\
(1,5 \%)\end{array}$ \\
\hline $\begin{array}{c}\text { SISTEMA } \\
\text { TUTOR } \\
\text { INTELIGENTE } \\
(2,3 \circ)\end{array}$ & $\begin{array}{c}\text { AVALIAÇ̃̃O DA } \\
\text { APRENDIZAGEM } \\
(1,3 \%)\end{array}$ & $\begin{array}{c}\text { FORMAÇÃO DE } \\
\text { PROFESSORES } \\
\left(1,1 \frac{1}{0}\right)\end{array}$ & $\begin{array}{c}\text { ENSINO } \\
\text { FUNDAMENTAL } \\
(1,5 \%)\end{array}$ \\
\hline
\end{tabular}

Tabela 5: Expressões mais frequentes por períodos de anos - SBIE
Com relação a veículos e representações do conhecimento, destacam-se no SBIE: OBJETOS DE APRENDIZAGEM (a partir de 2003), MAPAS CONCEITUAIS (2003 a 2010) são as expressões mais frequentes desde 2003.

Aspectos metodológicos de pesquisa são mais evidenciados a partir de 2003 (ESTUDO DE CASO, AVALIAÇÃO e MAPEAMENTO SISTEMÁTICO).

Assim como na RBIE, a expressão REALIDADE AUMENTADA ganha destaque nos últimos anos, ao lado de outras tecnologias (DISPOSITIVOS MÓVEIS e REDES SOCIAIS).

Conceitos como INCLUSÃO DIGITAL e a referência a pessoas com deficiência aparecem com frequência nos anos de 2003 a 2010, e não aparecem com frequência nos títulos dos trabalhos dos anos mais recentes (2011-2014).

Os qualificativos mais frequentes para APRENDIZAGEM são o COOPERATIVO E COLABORATIVO , até 2010 .

\subsection{WIE (2003, 2005-2014)}

No período de tempo analisado (anos 2003, 2005 a 2014), o WIE agrupa 596 trabalhos de 1402 autores. Os cinco autores com mais publicações no workshop apresentam 35, 11, 10, 10, 8 trabalhos, respectivamente. A Figura 7 apresenta a tagcloud dos autores com pelo menos quatro trabalhos publicados no WIE no período.

Com relação a redes de coautoria, existem 273 redes, das quais $11.72 \%$ (32) são de uma só pessoa. A Tabela 6 mostra o agrupamento de todas as redes. A maior rede no WIE no período é de 126 autores, que representa 8,99\% do total de autores.

Os quatro primeiros autores com mais publicações pertencem à mesma rede, a rede de maior tamanho. O quinto autor pertence a uma rede que agrupa 28 autores.

Analisando o contexto das palavras de maior destaque, encontramos resultados muito similares ao da revista RBIE e aos do evento SBIE, indicando um alinhamento de interesses da comunidade. A Figura 8 ilustra as tag-

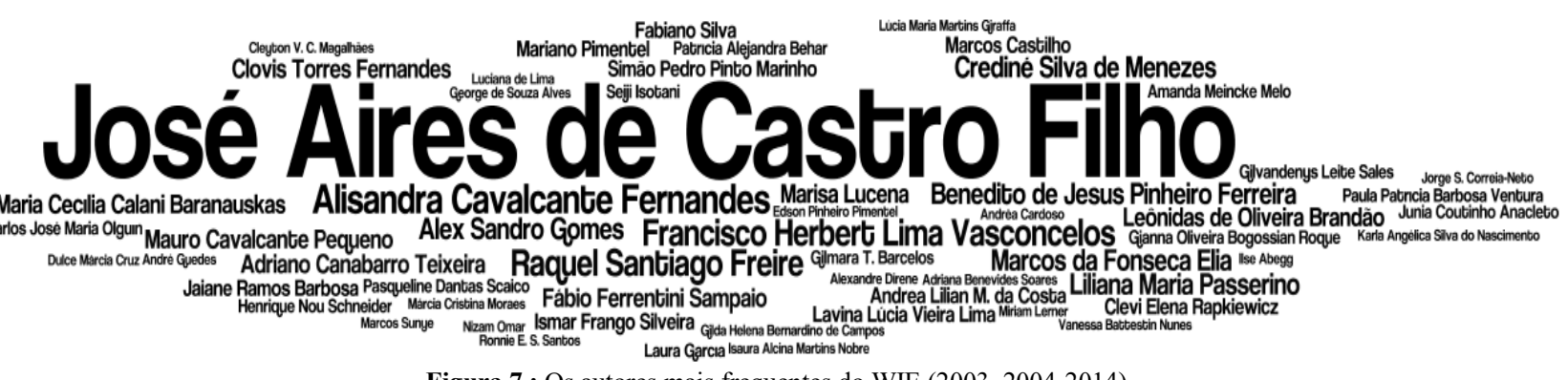

Figura 7 : Os autores mais frequentes do WIE (2003, 2004-2014) 
clouds dos títulos e dos resumos do WIE.

\begin{tabular}{c|c|c}
\hline $\begin{array}{c}\text { Quantidade } \\
\text { de Autores }\end{array}$ & $\begin{array}{c}\text { Quantidade } \\
\text { de Redes }\end{array}$ & $\begin{array}{c}\text { Porcentagem ao } \\
\text { total de redes }\end{array}$ \\
\hline 1 até 5 & 231 & $84,62 \%$ \\
\hline 6 até 10 & 27 & $9,89 \%$ \\
\hline 11 até 15 & 3 & $1,10 \%$ \\
\hline 16 até 20 & 4 & $1,47 \%$ \\
\hline 21 até 25 & 4 & $1,47 \%$ \\
\hline 26 ou mais & 4 & $1,47 \%$
\end{tabular}

Tabela 6: Redes de coautoria do WIE (2003, 2005-2014)

Por outro lado, podemos observar as especificidades do evento WIE especialmente o foco de interesse na formação; isto se evidencia em expressões como Formação de Professores, Formação Continuada, Relato de experiências, Learning Process, entre outros.

Com relação a níveis do ensino, prevalecem Ensino Fundamental e Ensino Médio.

As expressões presentes na Tabela 7 são as mais frequentes ao longo dos anos para o WIE. Observa-se que INCLUSÃO DIGITAL têm destaque e se mantem frequente em todo o período (2003-2016); a expressão (UM) COMPUTADOR POR ALUNO ganha destaque a partir de 2011. Ambas as expressões fazem referência a pesquisas voltadas a incentivos governamentais para inclusão digital dos estudantes brasileiros.

SALA DE AULA é uma expressão frequente ao longo de todos os períodos, indicando o contexto principal das pesquisas; essa expressão não ocorre entre as mais

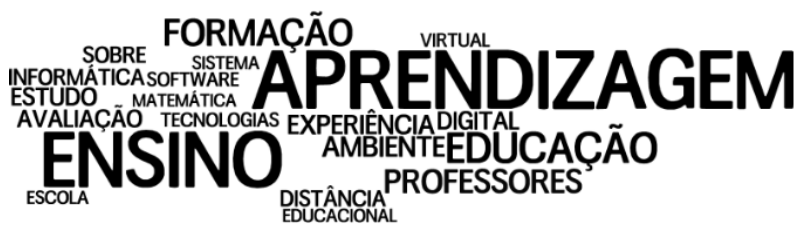

(a)

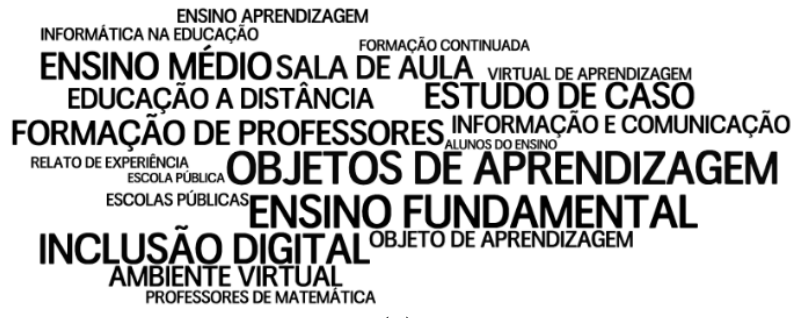

(c) frequentes na RBIE e no SBIE. ENSINO FUNDAMENTAL E ENSINO MÉDIO caracterizam o foco de interesse ao longo de todo o período.

Diferentemente da RBIE e do SBIE, não é possível encontrar, entre as expressões mais recorrentes, tecnologias contemporâneas. Aspectos de tecnologia estão representados em SOFTWARE EDUCATIVO, JOGOS EDUCACIONAIS E EDUCAÇÃO A DISTÂNCIA.

\begin{tabular}{|c|c|c|}
\hline $2003-2006$ & $2007-2010$ & $2011-2014$ \\
\hline $\begin{array}{c}\text { OBJETO (S) DE } \\
\text { APRENDIZAGEM } \\
(5,2 \%)\end{array}$ & \multirow{10}{*}{$\begin{array}{c}\text { OBJETO (S) DE } \\
\text { APRENDIZAGEM } \\
(10,4 \%) \\
\text { INCLUSÃO DIGITAL } \\
(5,4 \%) \\
\text { ENSINO FUNDAMENTAL } \\
(5,0 \%) \\
\text { ESTUDO DE CASO } \\
(3,5 \%) \\
\text { EDUCACÃ̃O } \\
\text { A DITTANCIA } \\
(3,0 \%) \\
\text { SALA DE AULA } \\
(3,0 \%) \\
\text { SOFTWARE LIVRE } \\
(3,0 \%) \\
\text { AMBIENTE VIRTUAL } \\
(2,5 \%) \\
\text { ENSINO MÉDIO } \\
(2,5 \%) \\
\text { JOGOS EDUCACIONAIS } \\
(2,0 \%)\end{array}$} & $\begin{array}{l}\text { ENSINO MÉDIO } \\
(4,6 \%)\end{array}$ \\
\hline $\begin{array}{l}\text { GEOMETRIA } \\
\text { DINÂMICA }\end{array}$ & & $\begin{array}{l}\text { FORMAÇÃO DE } \\
\text { PROFESSORES } \\
(4,6 \%)\end{array}$ \\
\hline $\begin{array}{c}(3,9 \%) \\
\text { AMBIENTE VIRTUAL } \\
(3,2 \%)\end{array}$ & & $\begin{array}{c}\text { ENSINO } \\
\text { FUNDAMENTAL } \\
(4,2 \%)\end{array}$ \\
\hline $\begin{array}{l}\text { ENSINO } \\
\text { FUNDAMENTAL }\end{array}$ & & $\begin{array}{l}\text { ESTUDO DE CASO } \\
\left(3,3 \frac{0}{6}\right)\end{array}$ \\
\hline $\begin{array}{c}\text { ENSINO MÉDIO } \\
(2,6 \%)\end{array}$ & & $\begin{array}{c}\text { COMPUTADOR POR } \\
\text { ALUNO } \\
(2,9 \%)\end{array}$ \\
\hline $\begin{array}{l}\text { ESTUDO DE CASO } \\
(2,6 \%)\end{array}$ & & $\begin{array}{l}\text { INCLUSÃO DIGITAL } \\
(2,9 \%)\end{array}$ \\
\hline 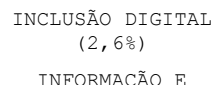 & & $\begin{array}{c}\text { INFORMAÇ̃̃O E } \\
\text { COMUNICAÇ̃̃O } \\
(2,9 \%)\end{array}$ \\
\hline $\begin{array}{c}(2,6 \%) \\
\text { COMUNICAC̃̃ }\end{array}$ & & 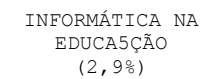 \\
\hline $\begin{array}{c}\text { SALA DE AULA } \\
(2,6 \%)\end{array}$ & & $\begin{array}{c}\text { SALA DE AULA } \\
(2,9 \%)\end{array}$ \\
\hline $\begin{array}{l}\text { SOFTWARE } \\
\text { EDUCATIVO } \\
\left(2,6 \frac{2}{\circ}\right)\end{array}$ & & $\begin{array}{c}(2,9 \%) \\
\text { EDUCACÃO } \\
\text { A DISTANCIA } \\
(2,5 \%)\end{array}$ \\
\hline
\end{tabular}

Tabela 7: Expressões mais frequentes por períodos de anos - WIE

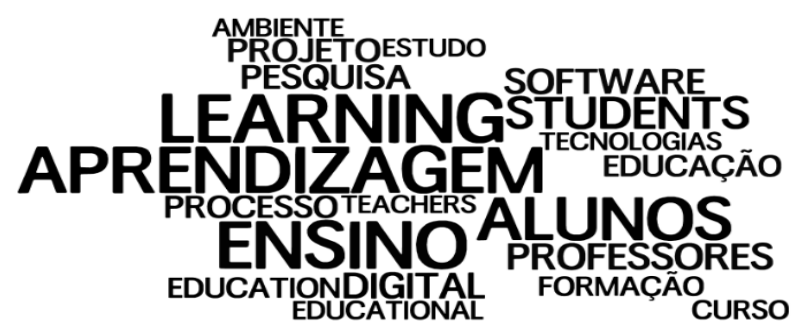

(b)

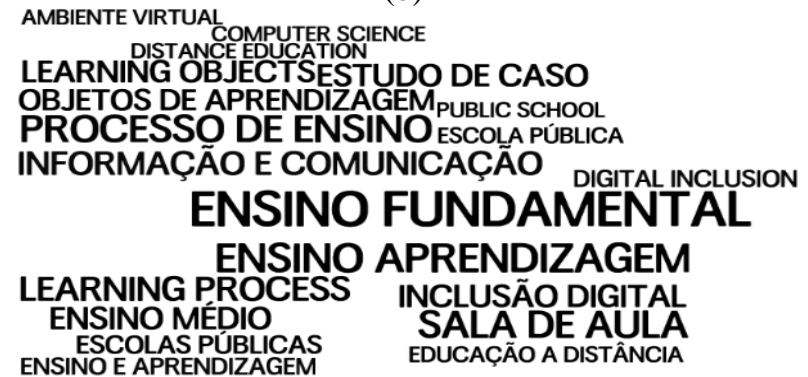

(d)

Figura 8 : Tagcloud dos títulos e dos resumos do WIE (2003, 2005-2014): a) palavras recorrentes nos títulos, b) palavras recorrentes nos resumos; c) expressões recorrentes nos títulos, d) expressões recorrentes nos resumos 


\section{AMBIENTE
PROFESSORESREALIDADE
JOGO
SISTEMA
ENSUCAÇÃO APRE DESENVOLVIMENTO}

(a)

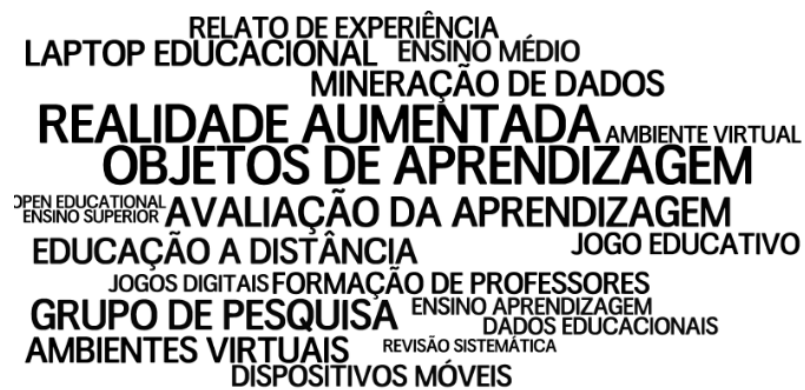

(c)

\section{OBJETIVO \\ PESQUISAPROJETO FERRAMENTA EDUUA Ã AMBIENTE TECNOLOGIAS EDUCAÇAOO DESENVOLVIMENTO FORMAÇÃOENSINO RESULTADOS
PROCESSO}

(b)

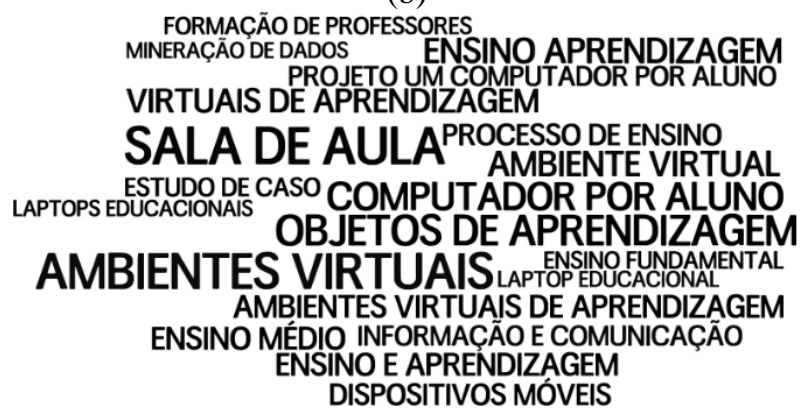

(d)

Figura 10 : Tagcloud dos títulos e dos resumos do CBIE (2012-2014) : a) palavras recorrentes nos títulos, b) palavras recorrentes nos resumos; c) expressões recorrentes nos títulos, d) expressões recorrentes nos resumos

\subsection{CBIE (2012-2014)}

Desde sua primeira edição, em 2012 até 2014 inclusive, o CBIE agrupa 250 trabalhos de 814 autores. Os cinco autores com mais publicações no congresso contribuíram com $13,7,6,6,5$ trabalhos, respectivamente. Uma lista dos autores com quatro ou mais publicações no período pode ser vista na Figura 9 em forma de uma tagcloud.

Com relação a redes de coautoria, existem 179 redes, das quais $11.17 \%$ (20) são de uma só pessoa. A Tabela 8 mostra o agrupamento de todas as redes. A rede maior no CBIE no período é de 27 autores que representa 3,32\% do total de autores.

Os cinco autores com um maior número de artigos pertencem a diferentes redes. No entanto, todas têm mais de dez membros, respectivamente: $21,12,27,11$, e 11 autores.

As palavras com maior frequência podem ser observadas no contexto em que elas se encontram, conforme Figuras 10-c e 10-d; vale notar a presença de destaque para MINERAÇÃO DE DADOS, que ainda não havia aparecido com tal frequência nos veículos anteriores (RBIE, SBIE, WIE).

\begin{tabular}{c|c|c}
\hline $\begin{array}{c}\text { Quantidade } \\
\text { de Autores }\end{array}$ & $\begin{array}{c}\text { Quantidade } \\
\text { de Redes }\end{array}$ & $\begin{array}{c}\text { Porcentagem ao } \\
\text { total de redes }\end{array}$ \\
\hline 1 até 5 & 138 & $77,09 \%$ \\
\hline 6 até 10 & 26 & $14,53 \%$ \\
\hline 11 até 15 & 8 & $4,47 \%$ \\
\hline 16 até 20 & 3 & $1,68 \%$ \\
\hline 21 até 25 & 3 & $1,68 \%$ \\
\hline 26 ou mais & 1 & $0,56 \%$
\end{tabular}

Tabela 8: Redes de coautoria do CBIE (2012-2014)

As expressões mais frequentes que aparecem entre 3 anos (2012 - 2014) do CBIE, são: OBJETOS DE APRENDIZAGEM (9), REALIDADE AUMENTADA (9), AVALIAÇÃO DA APRENDIZAGEM (7), GRUPO DE PESQUISA (7), AMBIENTES VIRTUAIS (6), EDUCAÇÃO A DISTÂNCIA (6), LAPTOP EDUCACIONAL (6), MINERAÇÃO DE DADOS (6), DISPO-

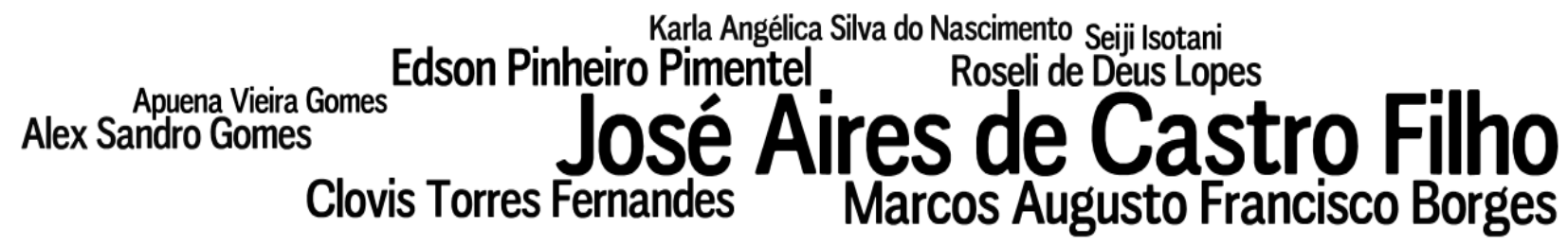

Figura 9 : Os autores mais presentes do CBIE (2012-2014) 
SITIVOS MÓVEIS (5) e ENSINO MÉDIO (5). Se analisarmos as expressões, percebe-se que existe predomínio de expressões tecnológicas nos títulos e resumos do CBIE (ex. OBJETOS DE APRENDIZAGEM - Figuras 10-c e 10-d) se comparadas às outras expressões frequentes (ex. AVALIAÇÃO DA APRENDIZAGEM (7)). Assim como RBIE e SBIE o termo REALIDADE AUMENTADA aparece em destaque. Também presente no SBIE, o termo DISPOSITIVOS MÓVEIS aparece em destaque no CBIE. Semelhante ao WIE, que destaca termos como INCLUSÃO DIGITAL e COMPUTADOR POR ALUNO, o termo LAPTOP EDUCACIONAL aparece em destaque no CBIE.

\section{Discussão}

A seção anterior apresentou os quatro veículos de publicações separadamente ressaltando: os autores mais frequentes, as redes de coautoria de cada evento e sua distribuição por tamanho, as palavras e as expressões mais frequentemente encontradas nos títulos e nos resumos dos trabalhos. Ao observar os dados em conjunto, pode-se ver que a porcentagem de redes por agrupamento por evento (Figura 11, resumo das Tabelas 2, 4, 6 e 8) é similar em todos os eventos. Assim, por exemplo, a maioria das redes tem tamanho entre 1 e 5 autores, independentemente do evento.

Esta informação deve ser completada com a distribuição da porcentagem de autores por agrupamento (Figura 12). Esta distribuição permite observar, por exemplo, que no SBIE a maior quantidade de autores está agrupada em redes de tamanho maior, especificamente 1596 autores, que representa $54,4 \%$ dos autores. Este valor inclui a rede de maior tamanho que se mencionou na seção relativa ao SBIE, mais os 193 autores que pertencem às outras redes de 26 ou mais autores. Isto pode ser um indicativo de maior coesão da comunidade do SBIE em torno de interesses em comum. Nos demais veículos, predominam as redes de menor tamanho. A porcentagem de autores em redes de menor tamanho no caso do CBIE pode ser devida ao fato de este ser ainda um evento recente.

A Figura 12 também revela que a maior quantidade de autores ou está em rede de no máximo 5 autores ou em redes de mais de 25 autores principalmente no SBIE, mas também no WIE.
Analisando os autores que tiveram 3 ou mais trabalhos nas 4 fontes de publicações analisadas, temos (ver Tabela 9): 1) Somente 3 autores publicaram nas quatro fontes de pesquisa; 2) $320(81,84 \%)$ autores publicaram somente em uma das fontes. 3) Somente 18,16\% publicaram em mais de uma fonte de pesquisa.

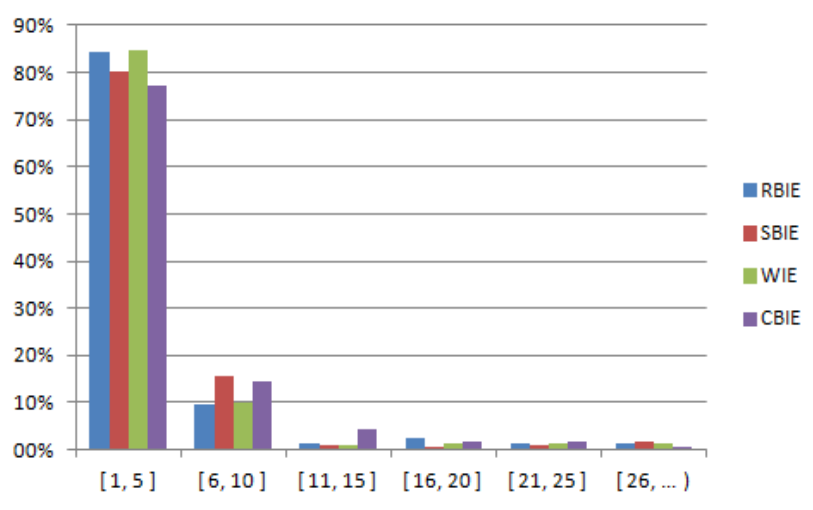

Figura 11 : Porcentagem de redes de coautoria por agrupamento

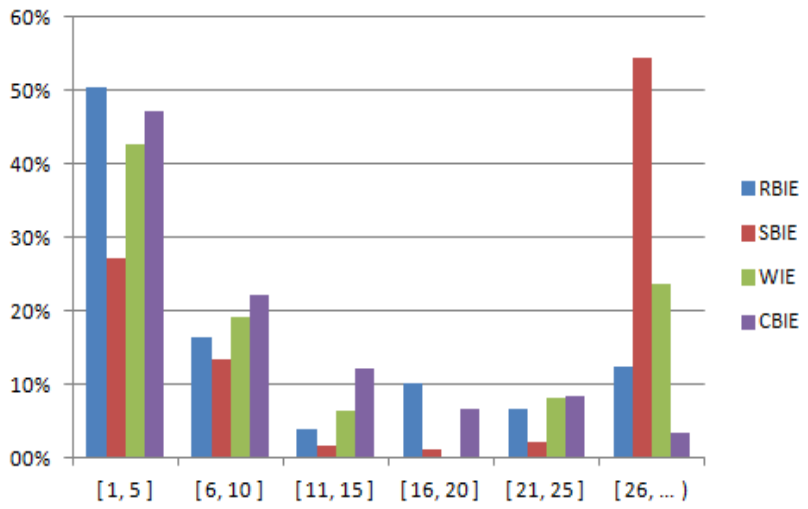

Figura 12 : Porcentagem de autores por agrupamento

\begin{tabular}{c|c|c}
\hline $\begin{array}{c}\text { Quantidade } \\
\text { de Eventos }\end{array}$ & $\begin{array}{c}\text { Quantidade } \\
\text { de Autores }\end{array}$ & $\begin{array}{c}\text { Porcentagem do } \\
\text { total de Autores }\end{array}$ \\
\hline 4 & 3 & $0,77 \%$ \\
\hline 3 & 15 & $3,84 \%$ \\
\hline 2 & 53 & $13,55 \%$ \\
\hline 1 & 320 & $81,84 \%$
\end{tabular}

Tabela 9: Quantidade de Autores que Publicaram por Evento 
A Tabela 10 e a Figura 13 mostram com mais detalhes a relação e porcentagem do número autores presentes na Tabela 9 que publicaram nos eventos analisados. Entre estes mais de $65 \%$ dos autores publicaram somente no SBIE. Analisando individualmente a Tabela 10 e Figura 13, temos: 1) entre os 15 autores que publicaram em 3 veículos, $12(80 \%)$ publicaram em sua maioria na RBIE, SBIE e WIE; 2) não temos autores com 3 ou mais publicações conjuntamente no RBIE e CBIE, nem no RBIE, WIE e CBIE; isto pode ser explicado pelo fato de o CBIE ser ainda recente.

Analisando somente a RBIE na Tabela 10 e Figura 13, onde temos autores com 3 ou mais publicações independentemente dos veículos, temos que $10,1 \%$ dos autores publicaram na RBIE; entre estes (considerados como $100 \%$ ): $12,9 \%$ publicaram somente na RBIE; $42,6 \%$ publicaram na RBIE e também no SBIE; 30,7\% publicaram na RBIE e no WIE. Isso quer dizer que os autores que publicaram na RBIE também publicam com maior frequência no SBIE

Analisando somente os eventos (SBIE, WIE e CBIE) e os autores com 3 ou mais publicações (Tabela 10 e Figura 13), temos: 1) somente dois autores publicaram nos três eventos $(0,5 \%$ dos dados analisados $), 2)$ o evento com o número maior de autores com 3 publicações é o SBIE (82.6\%) seguido do WIE $(25.6 \%)$ e do CBIE $(5.4$ \%). 3) a maior intersecção de autores com 3 ou mais publicações entre dois eventos é de $7.4 \%$ e se refere às publicações do SBIE e WIE.

\begin{tabular}{c|c|c}
\hline Eventos & $\begin{array}{c}\text { Quantida- } \\
\text { de de } \\
\text { Autores }\end{array}$ & $\begin{array}{c}\text { Porcentagem } \\
\text { do total de } \\
\text { Autores }\end{array}$ \\
\hline RBIE SBIE WIE CBIE & 3 & $0,8 \%$ \\
\hline RBIE SBIE CBIE & 1 & $0,3 \%$ \\
\hline RBIE SBIE WIE & 12 & $3,1 \%$ \\
\hline SBIE WIE CBIE & 2 & $0,5 \%$ \\
\hline RBIE SBIE & 17 & $4,3 \%$
\end{tabular}

\begin{tabular}{c|c|c} 
RBIE WIE & 1 & $0,3 \%$ \\
\hline SBIE CBIE & 4 & $1,0 \%$ \\
\hline SBIE WIE & 29 & $7,4 \%$ \\
\hline WIE CBIE & 2 & $0,5 \%$ \\
\hline RBIE & 5 & $1,3 \%$ \\
\hline CBIE & 255 & $65,2 \%$ \\
\hline WIE & 9 & $2,3 \%$ \\
\hline
\end{tabular}

Tabela 10: Quantidade de Autores que Publicaram por Evento

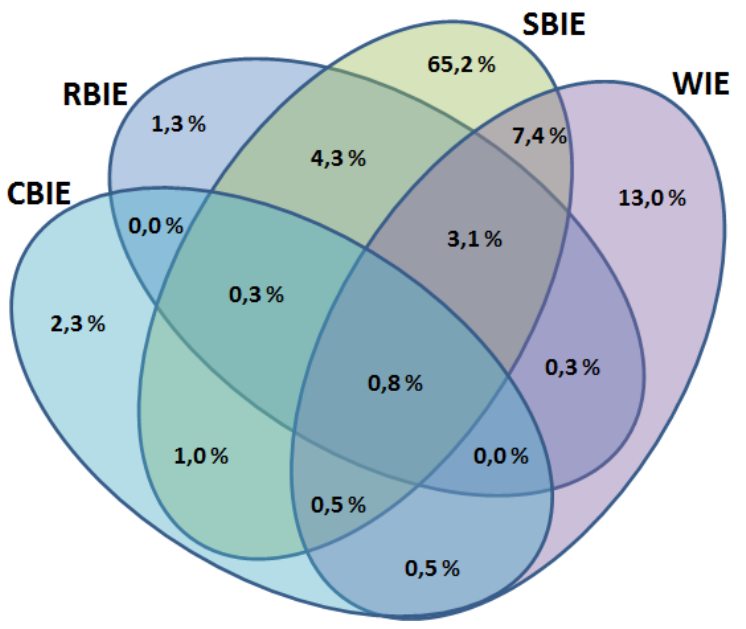

Figura 13 : Conjunto de autores por fonte de pesquisa

Se considerarmos os autores com 20 ou mais publicações independentemente do evento, temos um total de 18 autores (tagcloud da Figura 14). Somente 3 desses autores publicaram nos 4 veículos. Outro dado evidenciado é que, se analisarmos os autores mais frequentes de cada evento de forma individual (Figuras 5, 7 e 9), existe uma diferença muito grande de frequência entre esses autores (representada nos tamanhos das letras). No caso da RBIE este cenário muda, e os autores aparecem com frequência

\section{Leônidas de Oliveira Brandão Nizam Omar
Maria Cecilia Calani Baranauskas Cury Fábio Ferrentini Sampaio Alex Sandro Gomestugo ouks Crediné Silva de Meneatricia Alejandra Behar Crediné Silva de Menezes Clovis Torres errnandesjosé Aires de Castro Filho Edson Pinheiro Pimentellg Ibert Bittencourt Marcos da Fonseca Elia Junia Coutinho Anacleto}

Figura 14: Autores com 20 ou mais publicações considerando todas as fontes de publicação (RBIE, SBIE, WIE e CBIE) 
menos diferenciada (Figura 3).

A Tabela 11 mostra o número de palavras (coluna 2) com frequência maior ou igual a 10 e que aparece em determinado tipo de publicação (coluna 1). Por exemplo, se considerarmos as quatro fontes de publicação temos um total de 20 palavras $(8.93 \%)$ que aparecem em todas estas fontes, 26 palavras que aparecem somente em 3 fontes, e assim sucessivamente. Ao todo, 224 palavras com esta frequência foram encontradas, considerando todas as publicações analisadas.

\begin{tabular}{c|c|c}
\hline $\begin{array}{c}\text { Quantidade } \\
\text { de Fontes }\end{array}$ & $\begin{array}{c}\text { Quantidade } \\
\text { de Palavras }\end{array}$ & $\begin{array}{c}\text { Porcentagem do } \\
\text { total de Palavras }\end{array}$ \\
\hline 4 & 20 & $8,93 \%$ \\
\hline 3 & 26 & $11,61 \%$ \\
\hline 2 & 48 & $21,43 \%$ \\
\hline 1 & 130 & $58,04 \%$ \\
\hline
\end{tabular}

Tabela 11: Quantidade de palavras por fonte de pesquisa

A Figura 15 mostra a tagcloud com as 20 palavras mais frequentes que aparecem em todos os veículos analisados. Além do foco principal das quatro fontes de publicações estar de forma consistente em APRENDIZAGEM e ENSINO, outras palavras que têm destaque estão relacionadas a ambientes (virtuais) e ferramentas para a Educação a Distância, seu desenvolvimento e avaliação .

A Tabela 12 mostra em detalhes a distribuição destas 224 palavras entre as fontes de publicações analisadas. Além das 20 palavras que aparecem em todas as fontes, as palavras mais frequentes da RBIE estão mais alinhadas às palavras que aparecem no SBIE (18 palavras - soma de 12 palavras da interseção entre "RBIE SBIE WIE") com 6 palavras da interseção entre "RBIE SBIE") e depois no WIE (12 palavras ("RBIE SBIE WIE" com 12 palavras, e "RBIE WIE" vazia)). As 12 palavras comuns que aparecem entre RBIE, SBIE e WIE são: OBJETOS, WEB, DIGITAL, SOFTWARE, VIRTUAIS, MODELO, ESTUDO, ANÁLISE, MATEMÁTICA, APRENDIZADO, UTILIZAÇÃO, CURSOS. As 6 palavras adicionais que aparecem somente na RBIE e SBIE são: SISTEMAS,
SUPORTE, ABORDAGEM, AUTORIA, AGENTES, PROCESSOS. Nos casos que não aparecem na Tabela 12 (ex. "RBIE WIE"), a interseção entre as palavras com frequência maior ou igual a 10 é vazia.

\begin{tabular}{c|c|c}
\hline Eventos & $\begin{array}{c}\text { Quantida- } \\
\text { de de } \\
\text { Palavras }\end{array}$ & $\begin{array}{c}\text { Porcentagem } \\
\text { do total de } \\
\text { palavras }\end{array}$ \\
\hline RBIE SBIE WIE CBIE & 20 & $8,93 \%$ \\
\hline RBIE SBIE WIE & 12 & $5,36 \%$ \\
\hline SBIE WIE CBIE & 14 & $6,25 \%$ \\
\hline RBIE SBIE & 6 & $2,68 \%$ \\
\hline SBIE CBIE & 3 & $1,34 \%$ \\
\hline SBIE WIE & 38 & $16,96 \%$ \\
\hline WIE CBIE & 1 & $0,45 \%$ \\
\hline SBIE & 116 & $51,79 \%$ \\
\hline CBIE & 1 & $0,45 \%$ \\
\hline
\end{tabular}

Tabela 12: Quantidade de palavras por fonte de pesquisa

Analisando as palavras que aparecem nos eventos analisados temos um maior número de palavras comuns entre SBIE e WIE. Por exemplo: PROCESSO, INCLUSÃO, INTELIGENTE, SOCIAL, ATIVIDADES, CASO, CONTEXTO, REDE, COLABORATIVA.

As expressões mais comuns às fontes de pesquisa RBIE, WIE e SBIE são ESTUDO DE CASO e SOFTWARE EDUCACIONAL. A relação entre SBIE e WIE apresenta-se com três expressões bastante recorrentes: INCLUSÃO DIGITAL, VIRTUAL DE APRENDIZAGEM, OBJETO DE APRENDIZAGEM, parece ser maior que a relação entre a revista e os eventos. A relação RBIE e SBIE parece ser um pouco maior, com duas expressões bastantes recorrentes (APOIO AO ENSINO e APRENDIZAGEM COLABORATIVA), do que a relação entre RBIE e WIE com uma única expressão (ENSINO FUNDAMENTAL).

Analisando a frequência de expressões relacionadas a

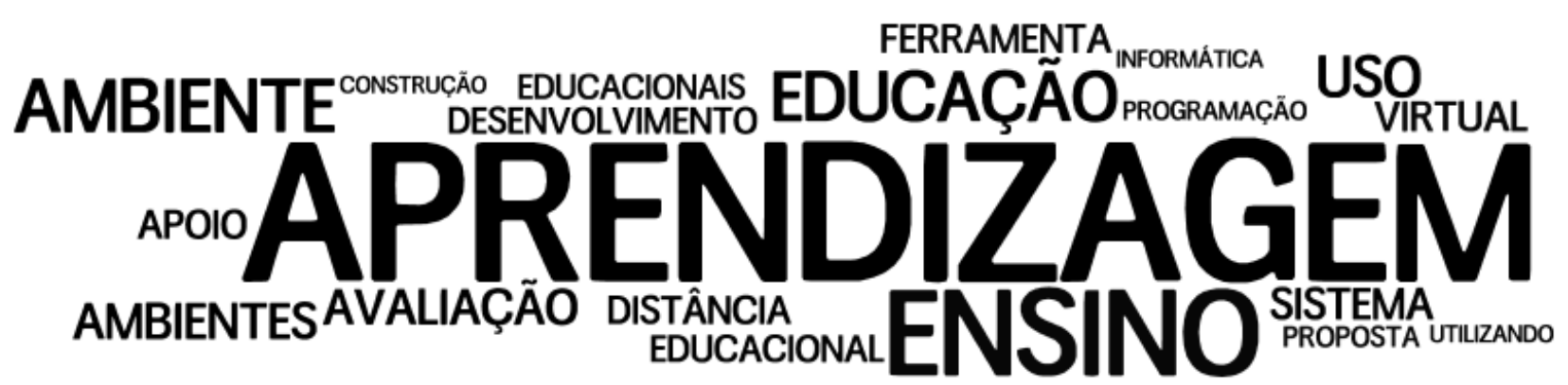

Figura 15: As vinte palavras comuns a todos os quatro eventos 
tecnologia e educação nos títulos e resumos dos trabalhos, os resultados sugerem que a frequência de referências à tecnologia (ex. DISPOSITIVOS MÓVEIS) e referências a educação (ex. APRENDIZAGEM COLABORATIVA) é semelhante independente da fonte analisada. Ainda, é possível perceber que determinados assuntos tomaram a atenção da comunidade em determinados momentos (ex. INCLUSÃO DIGITAL), assim como determinadas tecnologias (ex. LAPTOP, DISPOSITIVOS MÓVEIS), evidenciando e possivelmente refletindo mudanças tecnológicas sendo experimentadas..

\section{Conclusão}

A relação entre tecnologias digitais e sua apropriação em contextos educacionais envolve aspectos particulares de contextos acadêmicos e governamentais que impactam na pesquisa e sua prática. Pesquisas em informática na educação no Brasil vem sendo realizadas por comunidades de pesquisadores que usam como meio de divulgação as principais fontes de publicação de seus resultados de pesquisa, entre elas, a RBIE, o SBIE, o WIE e o CBIE. Neste sentido, analisar tais fontes de informação é uma maneira de caracterizar a comunidade identificando também novas oportunidades de ação na área.

Este artigo se utiliza do poder de representação de tagclouds (nuvens de palavras e expressões), criadas a partir dos títulos e resumos das contribuições, para ilustrar e discutir as principais diferenças e semelhanças entre as diferentes fontes. As tagclouds também evidenciam os principais autores da área em cada fonte de publicação e as redes de cooperação na comunidade.

De forma geral os resultados mostram que os atores principais da pesquisa estão distribuídos entre aos temas da educação e da tecnologia de forma equilibrada. No entanto, é possível identificar oportunidades de pesquisa envolvendo tecnologias, especialmente as contemporâneas, no campo de informática na educação, especialmente para a comunidade do WIE.

Os resultados também evidenciam que a proporção de expressões relacionadas com tecnologia e expressões relacionadas à educação se mantém de forma equilibrada ao longo dos anos, indicando não haver uma ênfase maior em um dos lados. Também não existe uma variação muito grande entre os termos mais frequentes independentemente da conferência analisada, indicando um compartilhamento coeso de interesses da comunidade em torno de determinados temas em determinados momentos (ex. INCLUSÃO DIGITAL).

Analisando aos autores em cada fonte pela frequência de seus trabalhos, a RBIE tem uma distribuição mais uniforme de alguns autores em relação aos demais. O mesmo não ocorre para os eventos analisados (SBIE,
WIE, CBIE), nos quais há autores com um grande número de publicações se comparados aos demais autores.

Com relação às redes de autores é possível perceber maior coesão do SBIE. Os principais autores de cada fonte analisada encontram-se nas maiores redes de coautoria, mas estas redes não são as mais frequentes do evento. Neste sentido, há espaço para a integração das pequenas redes de coautoria, unindo forças na exploração e pesquisa de diferentes temáticas.

Por fim, este trabalho não esgota o assunto; ao contrário, buscamos realizar um reconhecimento do território da informática na educação em nossa comunidade como uma preparação do terreno para novas contribuições. Em particular, trabalhos futuros poderão aprofundar o conhecimento em tópicos específicos, por exemplo avaliações e métodos de pesquisa, tecnologias específicas, entre outros, a partir do aqui levantado.

\section{Agradecimentos}

Este trabalho foi parcialmente financiado pela CAPES (processo \#01-P-1965/2012) e pela CNPq (processo \#162025/2014-9). Agradecemos também ao Instituto de Computação (ID) da UNICAMP e à Universidade do Quindio, Colômbia.

\section{Referências}

[1] MC de A. Armanda, R. L. Rodrigues, and V. C. Garcia. Um Mapeamento Sistemático para Problem Based Learning aplicado à Ciência da Computação. In: Anais do Workshop de Informática na Escola. Vol. 1. No. 1. 2012.

[2] D. Y. An, C. D. da Silva, D. M. G. Ribeiro, P. B. R. da Rocha, C. Maltinti, V. B. Nunes, and R. Fávero. Digita-um Jogo Educativo de Apoio ao Processo de Alfabetização Infantil. In Anais do Simpósio Brasileiro de Informática na Educação, vol. 24, no. 1, 2013.

[3] M.C.C. Baranauskas, J.E.G. Posada. Universal access to interaction as revealed by UAHCI words. Universal Access in Human-Computer Interaction. Design Methods, Tools, and Interaction Techniques for eInclusion. Springer Berlin Heidelberg, páginas 21-30, 2013.

[4] A. C. Barros, J. Wainer, K. Claudio, L. R. R. Ferreira, T. Dwyer. Uso de computadores no Ensino Fundamental e Médio e seus resultados empíricos: uma revisão sistemática da literatura. Revista Brasileira de Informática na Educação, v. 16, n. 1, página 57-68, 2008.

[5] S.B. Buchdid, and M.C.C. Baranauskas, HCI in 
context: What the Words Reveal About It. Proceedings of The 15th International Conference on Enterprise Information Systems, ICEIS 2013. vol3, p. 167-175, 2013

[6] S.B. Buchdid, and M.C.C. Baranauskas, IS THERE HCI IN IDTV?: an Exploratory Study on their Words. In: Proceedings of the 16th International Conference on Human-Computer Interaction, HCII'14. Springer, Berlin, DEU, página 47-57, 2014.

[7] CBIE, Congresso Brasileiro de Informática na Educação, www.br-ie.org/index.php/cbiemenu, Julho 2015.

[8] CEIE, Comissão Especial de Informática na Educação, www.br-ie.org, Julho 2015.

[9] D. Fallman. The new good: exploring the potential of philosophy of technology to contribute to human-computer interaction. In Proceedings of the SIGCHI Conference on Human Factors in Computing Systems. páginas 1051-1060, 2011.

[10] B. Kuo, T. Hentrich, B. M. Good, and M. D. Wilkinson. Tag clouds for summarizing web search results. In Proceedings of the 16th international conference on World Wide Web, páginas 1203-1204, 2007.

[11] J. W. P. Luz, and L. C. C. Fonseca. EduConnect: uma ferramenta de apoio à aprendizagem colaborativa para dispositivos móveis em redes MANET. In Anais do Simpósio Brasileiro de Informática na Educação, vol. 24, no. 1, 2013.

[12] F. A. C. Modesto, P. N. Mustaro, P. Notargiacomo. Revisão Sistemática para estudo de Interação Criança-Computador associada a RA e Jogos Digitais. In: Anais dos Workshops do Congresso Brasileiro de Informática na Educação, 2014.

[13] J.E.G. Posada, and M.C.C. Baranauskas. A Study on the Last 11 Years of ICEIS Conference-As Revealed by Its Words. International Conference on Enterprise Information Systems (ICEIS), páginas 100-111. 2014.

[14] RBIE, Revista Brasileira de Informática na Educação, http://www.br-ie.org/pub/index.php/rbie, julho 2015.

[15] A. W. Rivadeneira, D. M. Gruen, M. J. Muller, and D. R. Millen. Getting our head in the clouds: toward evaluation studies of tagclouds. In Proceedings of the SIGCHI conference on Human factors in computing systems, páginas 995-998, 2007.
[16] D. F. Rocha, I. I. Bittencourt, D. Dermeval, S. Isotani. Uma Revisão Sistemática sobre a Educação do Surdo em Ambientes Virtuais Educacionais. In Anais do Simpósio Brasileiro de Informática na Educação, Vol. 25, No. 1, página 1263-1272, 2014

[17] N. da Silva, S. Rogério, H. Ricardo M. Santos, A. A. de Souza, and W. O. dos Santos. Jogos Educacionais como Ferramenta de Auxílio em Sala de Aula. In Anais do Workshop de Informática na Escola, vol. 1, no. 1, 2013.

[18] SBIE (2014) Simpósio Brasileiro de Informática na Educação, www.brie.org/index.php/anaissbie, Julho 2015

[19] SBC, Sociedade Brasileira de Computação, www.sbc.org.br, Julho 2015.

[20] D.S. Soper, and O. Turel. An n-gram analysis of Communications 2000--2010. Communications of the ACM 55, no. 5, páginas 81-87, 2012.

[21] ToPA, Tool for Publication Analyzes, http://eurydice.nied.unicamp.br/ToPA/.

[22] C. Torezani, L. B. da Costa Chagas, and O. Lira Tavares. NewProg-um ambiente online para crianças aprenderem programação de computadores. In Anais do Workshop de Informática na Escola, vol. 1, no. 1, 2013.

[23] M. A. Trentin, C. A. S. Pérez, and A. C. Teixeira. A robótica livre no auxílio da aprendizagem do movimento retilíneo. In Anais do Workshop de Informática na Escola, vol. 1, no. 1, 2013.

[24] WIE, Workshop de Informática na Escola, www.br-ie.org/index.php/anaiswie, Julho 2015 